This item was submitted to Loughborough's Research Repository by the author.

Items in Figshare are protected by copyright, with all rights reserved, unless otherwise indicated.

\title{
Strategic complexities and opportunities in Welsh youth justice: exploring YJB Cymru
}

\section{PLEASE CITE THE PUBLISHED VERSION}

https://doi.org/10.1108/SC-05-2014-0007

\section{PUBLISHER}

(C) Emerald

VERSION

AM (Accepted Manuscript)

\section{PUBLISHER STATEMENT}

This work is made available according to the conditions of the Creative Commons Attribution-NonCommercialNoDerivatives 4.0 International (CC BY-NC-ND 4.0) licence. Full details of this licence are available at: https://creativecommons.org/licenses/by-nc-nd/4.0/

\section{LICENCE}

CC BY-NC-ND 4.0

\section{REPOSITORY RECORD}

Case, Stephen. 2019. "Strategic Complexities and Opportunities in Welsh Youth Justice: Exploring YJB Cymru”. figshare. https://hdl.handle.net/2134/31893. 


\title{
Strategic complexities and opportunities in Welsh youth justice: Exploring YJB Cymru
}

\begin{abstract}
A Strategic Insight Programme placement explored the role of the Youth Justice for Wales (YJB Cymru) in policy and practice development in the partially-devolved Welsh context. The placement employed multiple qualitative methods (interviews, observations, documentary analysis) and thematic analyses - identifying YJB Cymru's increasingly influential role in policy and practice development structures and processes in England and Wales more broadly and in Wales specifically. YJB Cymru exerts a dual influence - working with both government and practitioners to mediate and manage youth justice tensions in the complex, dynamic Welsh policy context through relationships of reflective and critical engagement.
\end{abstract}




\section{Strategic complexities and opportunities in Welsh youth justice: Exploring YJB Cymru}

This article presents and discusses the findings of a 'Strategic Insight Programme' placement exploring the Youth Justice Board for Wales (YJB Cymru). The Strategic Insight Programme (SIP) was launched to enable university researchers in Wales to develop and build relationships with external partner organisations (public, private, third sector) through short-term placements, with a view to gaining strategic insights into the operation of those partner organisations and building strategic partnerships for future collaborative projects and research activities (SIP 2013). To this end, in early 2013, the author approached established contacts in YJB Cymru to agree a short-term exploratory project with clear objectives:

1. to explore the role of YJB Cymru in youth justice policy and practice development structures, processes and relationships in Wales;

2. to provide opportunities for self-reflection (by YJB Cymru) on their existing practices and processes.

This paper seeks to examine, understand and explain the work of YJB Cymru, its current and future identity, roles and influences in the implementation of youth justice policy and practice across Wales in an ambiguous, complex and dynamic context of partial devolution.

\section{The youth justice context in Wales: Partially-devolved, entirely ambiguous}

Following the 'Misspent Youth' report (Audit Commission 1996) and the subsequent Crime and Disorder Act 1998, the overarching aim of the Youth Justice System of 
England and Wales has been to prioritise 'effective, efficient and economical' youth justice through a focus on 'prevent[ing] offending by children and young people' (Home Office 1998). Since April 2000, the operation of the Youth Justice System (YJS) has been overseen by a UK Government sponsored non departmental public body - the Youth Justice Board for England and Wales (see Souhami 2011; Pitts 2001), which provides 'independent' expert guidance and advice to the UK Government on the operation of the YJS. The Youth Justice Board (YJB) was charged with developing consistent standards and a coherent approach to youth justice by:

- monitoring the operation of the youth justice system

- advising the secretary of state on the operation of the youth justice system, national standards, and on how the aim of preventing offending by children and young people can most effectively be pursued

- identifying and disseminating effective practice across youth justice services

- making grants to YOTs and other organisations to support development and delivery of effective practice

- commissioning a distinct secure estate for young people

- placing young people in custody.

(YJB 2012a: 4)

A central driver of the YJB approach to its statutory responsibilities has been monitoring the performance of the YJS, particularly the practice of localised multiagency Youth Offending Teams. YJB performance monitoring of each local Youth 
Offending Team (YOT) has been animated by collection of statistical data on YOT workload and attainment of 'Key Performance Indicators' (measuring first-time entrants into the YJS, reoffending rates and custody rates ${ }^{1}$ ) and has been framed by the provision of detailed practice guidance relating to national standards, case management and evidence-based ‘Key Elements of Effective Practice’ (YJB 2008).

A particular strategic and operational challenge for the YJB has been the requirement to attend to the special case of Wales. Whilst the strategic direction of youth justice is set centrally by the UK Government Justice Minister and the YJB for England and Wales, the performance of the YJS in Wales is monitored collaboratively by the YJB Executive Management Group ${ }^{2}$ and YJB Cymru. For much of the life of the YJB, Wales has been defined as a 'YOT cluster region' in YJB structures and processes, rather than having its needs and issues considered in relation to its status as a separate country. However, when the YJB regional office structure was abolished in April 2012, the YJB Cymru office was retained and its status enhanced to that of a distinct YJB 'division' due to the particular policy complexities inherent to the Welsh youth justice context.

\section{Reconciling social policy and youth justice tensions in Wales}

'the political and organisational context in Wales, with partial devolution of relevant issues ... and a distinctive policy orientation for young people (rights-

\footnotetext{
${ }^{1}$ For YOTs in Wales, Key Performance Indicator data is also collected relating to education, training and employment, substance use and accommodation.

${ }^{2}$ It should be noted that the Board of the YJB is a distinct, non-devolved body, which has clear functions related to strategic and governance matters. The YJB Executive Management Group leads the Board's staff group and has a more operational emphasis. In this respect, the Welsh representative on the YJB is, therefore not a member of YJB Cymru's executive.
} 
and entitlements-focused), provides conceptual and practical space for progressive youth justice (Case and Haines 2012: 40)

There is a strong case to be made for the delivery of youth justice in Wales to receive special consideration on the basis of its (partial) devolution settlement and its social policy foci regarding children and young people. Since its partial devolution from the UK Government in 1999, the Welsh Government (formerly the Welsh Assembly Government) has reserved policy responsibility for several key areas affecting the lives of children and young people (e.g. education, social services, health, housing), but not for youth justice itself. Thus, while youth justice remains non-devolved, many of those who work in YJS in Wales are employed by organisations providing services under devolved authority. The tensions here become readily clear. The context of partial devolution has complicated the delivery of youth justice services in Wales due to the multi-agency composition of YOTs and the non-devolved status of youth justice. The practice of Welsh YOTs is monitored and influenced from the centre (YJB in London) in certain respects (e.g. requirements to provide data returns, adherence to prescribed National Standards for practice, statutory obligations to prioritise the prevention of offending ${ }^{3}$ ), yet they employ staff from devolved agencies (e.g. social services, education, substance use) working alongside staff from nondevolved agencies (e.g. police, probation) who may be working to different 'national' agendas and organisational priorities (e.g. enforcement vs welfare).

This structural tension has been further complicated by the principles of social policy

\footnotetext{
${ }^{3}$ The prevention agenda, paradoxically, is poorly serviced by YOTs in England, but emphasised in Wales by the Welsh Government, (c.f. the All Wales Youth Offending Strategy and the Youth Crime Prevention in Wales: Strategic Guidance - both co-authored by the Welsh Government and the YJB, in 2004 and 2008 respectively).
} 
making for children and young people in Wales, which are distinct from those in England. The Welsh Government has forged its own distinctive social and legislative identity in relation to working with children and young people, underpinned by collectivist and rights-based principles, promoting universal services over the more narrowly targeted (e.g. offence, offender and risk-based) provision typifying the ‘English’ approach. Welsh social policy for children and young people emphasises equality of outcome over the English focus on equality of opportunity (see Haines and Case 2011) and prioritises the engagement and participation of Welsh young people in decisions and services that affect them (Drakeford 2010; see also Haines 2009). This principled policy identity has been manifested in the Welsh Government's 'Extending Entitlement' youth inclusion strategy (outlining unconditional universal entitlement to support, guidance and services in ten key areas of a young person's life - National Assembly Policy Unit 2002) and the ‘Seven Core Aims’ for children and young people ${ }^{4}$ (Welsh Government 2004).

A series of bespoke structures have been created to develop the youth justice agenda in Wales in accordance with the distinct social policy for children and young people established by the Welsh Government. The Wales Youth Justice Advisory Panel is a quarterly (jointly-chaired) meeting between the Welsh Government and the YJB, which also includes representatives from YJB for England and Wales, Welsh YOTs, the Secure Estate, academics from the Welsh Centre for Crime and Social Justice and the voluntary sector. The lead YJB official with responsibility for this meeting is the Head of YJB Cymru. The Wales Youth Justice Advisory Panel (WYJAP) provides

\footnotetext{
${ }^{4}$ A flying start in life; access to education, training and learning opportunities; the best possible physical and mental, social and emotional health; access to play, leisure, sporting and cultural activities; be listened to, treated with respect and have their race and cultural identity recognized; a safe home and community; not disadvantaged by child poverty.
} 
expertise, challenge and scrutiny on the range of strategic, policy, practice and research issues relevant to youth justice in Wales and has the 'primary purpose to assist the Welsh Government and the YJB to implement policy that prevents offending and reoffending by children and young people in Wales' (YJB and Welsh Government 2014: 1). Within the Welsh Government, youth justice now sits as part of the Crime and Justice Team within the Community Safety Division. The Crime and Justice Team has responsibility for the interface between Welsh Government and criminal justice related policy from the Home Office and Ministry of Justice; including youth justice. The Crime and Justice Team's role is to liaise externally with YJB Cymru and internally with government colleagues in child-focus departments (e.g. mental health, education, social services, housing, substance use) in order to shape and influence policy development. There is also YOT Managers Cymru, a committee of all YOT managers in Wales (represented on the WYJAP), which meets to consider the implications of legislation, government guidelines and policy on youth offending in Wales and to determine effective responses (YOT Managers Cymru 2013). The monitoring and delivery of a youth justice sensitive and appropriate to the Welsh context, is further supported by a single Welsh representative on the YJB (one of the 12 individual board members), who also jointly-chairs the WYJAP. The Welsh representative ${ }^{5}$ works closely with YJB Cymru in a critical and developmental capacity because of their joint purpose in working through sensitive political and policy issues. Welsh interests and the unique devolved services-youth justice services relationship in Wales are acknowledged and addressed by the YJB through the work undertaken separately by the Welsh representative on the YJB and YJB

\footnotetext{
${ }^{5}$ The post of YJB member representing Wales evolved from recognition (e.g. by the Chair of the YJB) that Westminster, Wales and the devolved Welsh Government needed to cooperate through a balanced approach that provided the YJB with insight into issues that may require adjustment (to the Welsh context) prior to discussion. In this respect, the Welsh representative and YJB Cymru pursue the same objective.
} 
Cymru. Liaison between these two is essential and plays a significant role in their approach to gaining recognition and integration with new approaches that require implementation in Wales.

At the strategic level, the direction and implementation of youth justice in the Welsh social policy context is addressed directly through the 'All Wales Youth Offending Strategy' (WAG and YJB 2004), a partnership document, jointly-written by the Welsh Government and the YJB for England and Wales. The All Wales Youth Offending Strategy (AWYOS) acknowledges and addresses the issues facing Welsh YOTs in meeting the specific, technical practice requirements of the YJB for England and Wales, particularly the collection of data to enable them to monitor YOT performance in preventing youth offending through risk-based assessment and intervention and reconciling these with the broader, principled policy foci of the Welsh Government around universalism and children's rights. The AWYOS attempts to integrate YJB principles of 'prevention, 'early intervention', restorative justice measures, appropriate punishment and supported rehabilitation' with Welsh Government principles for 'promoting the welfare of children and young people [that] reduces the risk of offending and reoffending' - a distinctively Welsh objective alongside punishment - a distinctively English element (WAG and YJB 2004: 3; see also Haines 2009). At the time of its inception, the AWYOS created a somewhat ambiguous youth justice context in Wales, where both the YJB and the Welsh Government expressed a desire for prevention, yet sought to pursue this goal in practice through an uneasy, potentially incompatible mix of distinctly English objectives (e.g. punishment, responsibilisation) and distinctly Welsh objectives (e.g. welfare, children's rights). This dichotomous characterisation may be somewhat out- 
dated now and the youth justice context more nuanced. However, since replacing the Labour Government that introduced these English objectives, the Coalition Government has been largely silent on youth justice and other devolved issues, so the extent of evolution and nuance within youth justice policy remains largely hidden from the outsider. Similarly, although the YJB has committed to a move away from the risk focus in the assessment and intervention of young people, this is yet to commence in practice, so the assertion of a dichotomy (albeit generalised and broad brush) is, prima facie, still a defensible observation. The AWYOS is most notable, however, for initiating unique, Welsh-focused youth justice context whereby 'young people should be treated as children first and offenders second' (WAG and YJB 2004: 3), which directly challenges the risk-focused, responsibilising, adulterised and adultcentric youth justice emerging from England. The development and implementation of the AWYOS is monitored and guided by the WYJAP. A revised strategy, is in preparation and due for publication in April 2014

The emerging political, structural and operational emphases on a distinct Welsh or 'dragonised' youth justice (Haines 2009 - the dragon being the national symbol of Wales) has gained significant momentum in the past five years, in policy terms rather than necessarily in practice. Two simultaneous political agendas have progressed these emphases: the UK Coalition Government's incremental critical reviews of the YJB in England and Wales and Welsh Government report on devolving youth justice. UK Government reviews have indicated that the role of the YJB in England and Wales should incrementally diminished through: recommendations in the 'Breaking the Cycle' Green Paper (MOJ 2010) for its abolition as a cost-cutting measure in the age of austerity, a suggestion that was downsized by subsequent decisions for the 
maintenance of current functions (albeit in a reduced capacity) in the 'Public Bodies Act' (UK Government 2011) and most recently the reduction of YJB independence to make it more accountable to Ministers, expressed in the triennial 'Functions Review' (MOJ 2012). However, it can be argued that any reductions in YJB role have been more in perception than reality - with the reviews making recommendations for changes to functions that are actually already in place (so not changes or reductions in any substantive sense), but inconsistently applied in practice (e.g. Ministry of Justice representation at YJB meetings, more interface between the YJB and Government ministers). Similarly, none of YJB Cymru's functions have been reduced and two in particular have been strengthened: the power to give grants to YOTs (due to being enabled to hold YOTs to account for performance through an escalation process) and the ability to request ministerial intervention in poorly performing YOT areas. Furthermore, the Coalition Government’s ‘localism’ agenda has enabled YJB Cymru (within its existing legal powers and functions) to more fully realise its effective practice dissemination function by promoting practice more sensitive to the Welsh policy agenda through its Practice Development Panel and the use of the Correctional Program Assessment Inventory (a tool to evaluate criminal justice programme integrity). Concurrent to the UK Government reviews, the Welsh Government has been tentatively exploring the potential for a devolved youth justice settlement, which has been recommended by the Silk Commission's second report one in which key stakeholders in Wales (e.g. YJB Cymru) would have more responsibility and influence. The Welsh Government commissioned a large-scale review from Professor Rod Morgan (former Chair of the YJB), entitled 'Report to the Welsh Assembly Government on the question of Devolution of Youth Justice Responsibilities' (Morgan 2009), which was consolidated by the 'Devolution of Youth Justice' Cabinet 
Briefing (Welsh Government 2011). Both publications stopped short of advocating the devolution of youth justice policy-making responsibilities to Wales, with both asserting that the Welsh Government retains strategic and policy-making powers in several key (devolved) areas that influence youth justice, that more progress was possible in the youth justice arena within the current settlement and that a distinct Welsh youth justice is already emerging. Of particular note is Morgan's (2009) conclusion that there is a general lack of appetite for devolution amongst YOT managers in Wales because the current arrangements enable them to retain a degree of autonomy at the local level from the central YJB in England. A subsequent Welsh Government Green Paper ${ }^{6}$ (Welsh Government 2012) has moved discussion forward regarding how the Welsh Government can most effectively utilise its existing powers to progress a rights-focused youth justice context in Wales that benefits children and young people in the YJS. A White Paper on proposals for an Assembly Bill will focus on the specific group of young people who are at the greatest risk of reoffending and progressing further through the youth justice system into custody ${ }^{7}$. YOT managers reported that the complex constitutional arrangements nationally could be beneficial, enabling them to resist and/or embrace the YJB/English performance monitoring approach (centralised, prescribed and evaluated by Government in London) and the Welsh Government's 'children first offender second' ethos (for social policy more broadly and youth justice specifically) whichever they considered more appropriate - thus, they were able to 'play both sides' (Morgan 2009). In practice, however, the situation is more nuanced than this apparent policy dichotomy would suggest. There are individual differences in YOT performance and practice

\footnotetext{
${ }^{6}$ 'Proposals to improve services in Wales to better meet the needs of children and young people who are at risk of entering, or are already in, the Youth Justice System'.

${ }^{7}$ http://wales.gov.uk/consultations/people-and-communities/improving-services-for-young-people-inyouth-justice-system/?lang=en .
} 
ethos within and between England and Wales. These differences imply a potential disjuncture between Welsh Government social policy for children and young people and YOT practice in Wales. When this disjuncture is considered alongside the escalating agendas of ministerial accountability and a diminishing role for the YJB in England (UK/England) and the possible devolution of youth justice and an expanded role for YJB Cymru (Wales), the need for closer examination of youth justice in Wales is rendered increasingly important.

\section{Enter YJB Cymru}

A significant move towards addressing the policy and practice tensions in the context of an emerging 'distinct' Welsh youth justice was the creation of the YJB Cymru ${ }^{8}$ division, which sits alongside the Corporate Services, Effective Practice, Community and Secure Estate divisions on the YJB for England and Wales Executive Management Group. YJB Cymru has dual-facing responsibility for both implementing and mediating YJB policy in the Welsh context - advising its parent body on Welsh matters and monitoring, supporting and advising YOTs in Wales (YJB Cymru 2012a). In its ‘Blueprint for promoting effective practice and improving youth justice performance in Wales’, YJB Cymru outlines its official role as:

\section{- Working with UK Government}

- providing advice to ministers and working with officials in the Ministry of Justice to help them to take account of the potential impact of devolution when developing policy and legislation;

\footnotetext{
${ }^{8}$ YJB Cymru is sub-divided into three branches: Policy and Planning, Oversight and Support, Effective Practice and Innovation and has a total of 11 staff.
} 
- Working with Welsh Government

- developing a joint youth justice strategy and delivery plan for Wales [the AWYOS];

- collaborative monitoring of youth justice outcome information;

- joint government oversight of youth justice delivery;

- exchange of relevant information;

- collaboration in pursuit of effective and innovative practice;

- reciprocal advice on the interface between devolved and non-devolved policy;

- jointly convening the Wales Youth Justice Advisory Panel;

- accessing the voice of the young person - to ensure that the views and experiences of young people are taken into account.

(YJB Cymru 2012b: 5-6; emphasis added)

At the structural level, the Head of YJB Cymru sits as an equal partner on the YJB's Executive Management Group (EMG). A key part of this role for YJB Cymru representatives is to provide expert advice to the EMG and its 'Informational Decision Papers', each of which contains a standing 'Issues for Wales' section. In addition, the Head of YJB Cymru is a member of the WYJAP, which is co-chaired by the Welsh representative on the YJB and the Deputy Director of the Welsh Government Community Safety Division. YJB Cymru reports to each WYJAP meeting on the standing item 'Wales youth justice performance'.

At the operational level, YJB Cymru is invited, when appropriate, to attend for half a 
day of the bi-monthly, two-day YOT Managers Cymru meetings. This flexible partnership arrangement has evolved into attendance at every meeting, where YJB Cymru has a standing item slot for updates and areas requiring YOT manager approval. YJB Cymru representatives (Head of YJB Cymru, the heads of the Policy and Planning, Oversight and Support, Effective Practice and Innovation branches) also attend individual YOT Management Boards on an invitational basis, typically when they have been working in partnership with a YOT to support improvement on a specific practice issue (identified by either side as important) and there is a perceived need to introduce or disseminate this work to the Management Board.

\section{Gaining strategic insight into Welsh youth justice}

In the current climate of escalating devolution debates and an increasingly ‘dragonised’ youth justice (Haines 2009), at least in political, rhetorical and structural terms, there is a pressing need to explore the role of YJB Cymru at the structural and operational levels, and how its identity, roles, relationships and mechanisms influence the evolution and implementation of youth justice policy and practice across Wales. As stated at the outset of the paper, in early 2013, an opportunity for such an exploration presented itself through funding from the Wales-based 'Strategic Insight Programme' (SIP). The YJB Cymru SIP adopted a qualitative multiple methods approach to address its objectives. Purposive sampling was used to populate a tripartite methodology consisting of:

- Semi-structured interviews with key stakeholders: Head of YJB Cymru, all YJB Cymru heads of branch (Oversight and Support, Effective Practice and Innovation, Policy and Planning), Head of Crime and Justice, Welsh 
Government, the Welsh representative on the YJB for England and Wales, YOT managers and practitioners from North, Mid and South Wales (6/18 Welsh YOTs), police officers from Mid and South Wales, a Secure Estate manager;

- Observations of policy and practice mechanisms: YJB Cymru meetings (team meetings, practice development panels), YOT crime reduction and 'Bureau' (diversion) projects in four YOTs;

- Documentary analyses of YJB Cymru publications: YJB Cymru: A Blueprint for Promoting Effective Practice and Improving Youth Justice Performance in Wales (YJB 2012b); YJB Corporate Plan 2013-16 and Business Plan 2013/14 (YJB 2012a), YJB Effective Practice Identification and Dissemination (YJB 2012c), YJB Community Division Blueprint: Improving Outcomes in Community Youth Justice Services (YJB 2012d).

The YJB Cymru SIP project was conducted over a six-month period from February to July 2013. Sampling and access to policy documents, gatekeepers, key stakeholders, meetings and projects was facilitated by all YJB Cymru division heads and administrative support staff, although some practitioners were approached directly. Provisional qualitative findings and conclusions were fed back in a formal report to the SIP funding body and at a YJB Cymru divisional meeting and these findings and conclusions are elaborated below.

Thematic analysis of the qualitative data identified the central component of the role, 
operation and practices of YJB Cymru as critical engagement with partners. The nature of this critical engagement will now be explored, detailing the relationships and interactions between YJB Cymru and its three main key stakeholder partners: the UK Government (represented by the YJB for England and Wales), the Welsh Government (represented by the Crime and Justice Team) and Welsh YOTs. For ethical purposes of retaining anonymity amongst the small and easily recognisable key stakeholder interview sample, no direct quotes have been attributed.

\section{Critical engagement with government}

The central animator of the work of YJB Cymru can be clearly distinguished as being critical engagement. SIP feedback indicated that the main focus of engagement between YJB Cymru and the UK Government in London (Ministry of Justice and the YJB for England and Wales) was policy-related. YJB Cymru has been concerned to challenge any perceived Anglo-centric foci or neglect of Welsh concerns consistently and robustly stating the case for mediated policy sensitive to the Welsh context. YJB Cymru attempts to bridge the 'policy-practice divide' by advising government in order to 'try to help London to understand Wales'. Therefore, YJB Cymru engages critically with 'the centre' (YJB in London) to provide (Walesspecific) youth justice policy advice to the UK Government, constantly striving to 'influence the influencer'. Of course, simply by ‘being there' (in London) YJB Cymru serves as a constant reminder that Westminster and the YJB must pay due attention to the devolved authority in Wales and to the needs of Wales (in, for example, receiving an equal share of centrally distributed finances). Much of its influence, therefore, is to be found in minor details and the nuances of policy and strategy, such as the inclusion of short paragraph on the Bureau model in a Ministry of Justice/Youth Justice Board 
strategy paper on diversion (YJB 2013 ${ }^{9}$ ). There are, however, limits to the visibility of this influence and, moreover, inherent limits (quite justifiably) to the extent that Westminster is prepared to be influenced by Wales.

Specific obstacles to effective critical engagement with UK Government (more so than with the YJB for England and Wales) were highlighted, particularly a perceived insensitivity to the Welsh context from civil servants in London. Interview feedback suggested that this apparent insensitivity was felt to be largely due to a lack of experience of working with young people, combined with the central objective of civil servants to serve their ministers’ portfolios, resulting in overriding adherence to policy and legislation objectives driven by England. The SIP data portrayed critical engagement between YJB Cymru and the YJB for England and Wales as an evolving process. YJB Cymru has been allocated more responsibility and consideration 'from the centre and at the centre' in policy and practice development mechanisms and resultant policy is slowly becoming more sensitive to the Welsh context of youth justice. However, engagement with UK Government was not the main focus of the SIP and no staff located in England working for the Ministry of Justice or the YJB (apart from the Welsh representative) were interviewed. This highlights the potential for further exploration of these dynamics and relationships in future work.

The SIP data paints a more detailed picture of engagement between YJB Cymru and Welsh Government. Interview data suggested to the researcher that YJB Cymru

\footnotetext{
${ }^{9}$ The paper states that some areas have access to diversion schemes such as Triage, Youth Justice Liaison and Diversion and the Bureau model (Wales only) - many of which operate in partnership between the police and the YOT. It goes on to suggest that how these schemes fit into the out-of-court disposal framework will continue to be determined locally, essentially asserting a prescribed, nonnegotiable approach for England, yet flexibility for Wales to be more adaptive.
} 
pursues a Welsh-centric influence (in structural and policy-making terms) sensitive to the unique context of youth justice in Wales. YJB Cymru and the Welsh representative on the YJB in London 'take every opportunity to influence children's policy, devolved or otherwise, by working with Welsh Government ministers [notably the Minister for Local Government and Government Business], the Secure Estate, YOTs, the Children's Commissioner and police commissioners'. The nature of this 'influence' was understood from interviews as an ongoing process of critical engagement and reciprocity between YJB Cymru and the Welsh Government, particularly its Crime and Justice Team, whereby each partner offers test, challenge, critique and validation to the other. Purportedly, a context of overlapping needs, objectives, data sources and funding streams has emerged from and contributed to the ‘compatible philosophies’ of both YJB Cymru and the Crime and Justice Team, which has enabled them, where appropriate, to swap intelligence, share funding and collaborate on projects. For example, the Welsh Government provides funding for the 'Reintegration and Resettlement Programme' and the 'Complex Needs Programme' with the need for this funding identified through joint Welsh Government-YJB Cymru analysis of the needs of children and young people in Wales.

In the non-devolved policy context of youth justice in Wales, it is possible for the nature of the relationship between YJB Cymru and the Welsh Government (Crime and Justice Team) to fluctuate along a continuum from conflict to confluence. SIP data illustrates that a relationship more akin to confluence has been preferred in general and that an environment of mutual respect and trust has been nurtured. Interview testimony cited the utility of both parties possessing 'like-minded', 'accessible' and 'dynamic' individuals, who were able to engage with one another and 
with practitioners in a progressive and empathetic (Welsh-centric) manner. The nondevolved nature of youth justice in Wales, set alongside common ground between partners, clearly encourages and engenders a reciprocal relationship of engagement between YJB Cymru and Welsh Government, including a pervading sense of outcome focus, with both sides committed to 'improve life for young people in the Youth Justice System' in Wales. Examples of such life enhancing positive outcomes have been evidenced along a continuum of youth justice practice, from the use of diversion to reduce the numbers of young people entering the YJS for the first time (cf. the Bureau scheme - see Haines, Case, Charles and Davies 2013 and Triage in Cardiff ${ }^{10}$ ), the Complex Needs Programme for nuanced assessment and intervention within the formal YJS to the Reintegration and Resettlement Programme for young people transitioning out of the YJS.

The generally confluent nature of the relationship between YJB Cymru and the broader Welsh Government does not preclude certain tensions and the relationship is 'not without its difficulties'. Interviewees expressed concerns that the relationship can be 'hard to manage at times', mainly due to differing agendas and priorities, notably YJB requirements to 'develop an evidence base' (to inform policy generation) compared to Welsh Government requirements to 'generate policy' and a concurrent 'lack of resource capability' (e.g. researchers) to generate supportive evidence. Consequently, there is a constant need to mediate and mitigate these tensions based on the respective priorities of both parties and to take into account the Welsh Government's relative 'lack of control over youth justice policy' compared to its more extensive powers in devolved areas such as Education and Social Services. The

\footnotetext{
${ }^{10}$ https://www.justice.gov.uk/youth-justice/effective-practice-library/cardiff-triage
} 
‘tension' here relates to 'policy, which need not be based on evidence (what civil servants have to try to make real) versus delivery, which needs to be based on evidence rather than philosophy (what the public servants in the YJB try to do)'. The YJB Cymru-Welsh Government relationship, therefore, is influenced (at least in part) by a 'policy-delivery divide' wherein YJB Cymru (like its English parent organisation) feels the need to remain at 'arms length' in order to be able to critically engage with Welsh Government policy agendas and requirements where necessary (e.g. when policy is developed with a relative lack of evidence base) in order to mitigate this policy for appropriate delivery by youth justice practitioners. There is a perceived openness to guidance and critique on the Welsh Government side, with the Crime and Justice Team acknowledging YJB Cymru's influence over the development and implementation of youth justice policy in Wales. YJB Cymru works with Welsh Government colleagues to develop an evidence base that can influence how the UK Government exercises youth justice powers to the benefit of young people in Wales, typically through bespoke arrangements to accounts for devolved powers where necessary. YJB Cymru also acts as an open and transparent critic of Welsh Government policy where necessary, such as when it is felt that policy could be detrimental to young people in the YJS in Wales. Accordingly, the Crime and Justice Team can function (at times) as a messenger for and mediator of YJB Cymru concerns to its Welsh Government policy colleagues, although YJB Cymru can and does go directly to these policy colleagues. Here, the 'it' refers to the unique youth justice policy context in Wales that enables YJB Cymru to adopt a fluid and multifaceted identity (see also Souhami 2011) in order to serve the respective needs of key stakeholder partners. There is a danger, however, that such fluidity of role could be over-emphasised by key stakeholder perceptions. The role and influence of YJB 
Cymru may, to some degree, be shaped and restricted by its identity and role within the broader YJB for England and Wales and its inherent requirements to deliver and monitor centralised policy and practice agendas emerging from London. YJB Cymru could be compelled to function, to some extent, as a 'piggy in the middle' - caught between the requirements, priorities and agendas of England (UK Government and YJB for England and Wales) and Wales (Welsh Government and Welsh YOTs). The extent to which this role is a political inevitability and practical reality as opposed to a legitimate perception on the part of key stakeholders remains moot and inconclusive on the basis of the available SIP data. However, indications are that the nature of YJB Cymru-Welsh Government relationship mitigates these concerns to a degree, with the Crime and Justice Team able to translate YJB Cymru's delivery concerns into policy terms as a means of informing their policy colleagues in other departments. As with the YJB's engagement with the Ministry of Justice in London, YJB Cymru's arms length, independent status is a key factor in allowing this relationship to be mediated.

\section{Critical engagement with Welsh YOTs}

The nature of YJB Cymru's critical engagement with YOTs is underpinned by the critical friendship role that characterises its relationship with government in Wales and London. The nature of this 'engagement' with YOTs differs from that with government, in that it tends towards working in partnership to engender ownership of and commitment to practice development processes through critical reflection. The YJB SIP data identified a different aspect of engagement when considering YJB Cymru's relationships with practitioners - a closer, more multi-layered engagement focused on nurturing relationships of trust and support in order to 'bring YOTs along', involving them at all stages of practice development and engendering 
commitment and ownership of youth justice in Wales. Interviews with YJB Cymru staff made explicit their prioritisation of collaborative, partnership and joined-up working with YOT Managers Cymru and front-line practitioners working in YOTs and the Secure Estate. YJB Cymru's relationship with YOT Managers Cymru was described as 'changing rapidly and positively...an improvement from the historically sceptical, inward looking, negative YOT environments'. It was clear from interviewee testimony that a degree of reciprocal investment in the YJB Cymru-YOT Managers Cymru relationship was emerging, evidenced through the increasing numbers of YOT managers and staff on YJB Cymru project boards/reference groups and the increasingly amount of requests for support received by YJB Cymru from YOTs. In individual YOT terms, an equivalent reciprocal relationship was reported, with YJB Cymru involving YOT staff in the development and implementation of YJB projects at an early stage in order to benefit from 'on-the-ground' knowledge, engender practitioner ownership and achieve 'supportive engagement' designed to more effectively realise intended outcomes. Similarly, YOTs were being encouraged to solicit operational support and guidance from YJB Cymru branches to identify suitable project targets and methods of 'effective' resourcing, monitoring, delivery and evaluation.

Analysis of the SIP data highlights subtle differences in the nature of YJB Cymru's critical engagement with 'youth justice services', notably YOTs and the Secure Estate, (compared to its work with government) to the extent that it appears to be informed and driven by less formal 'softer, personalised processes of relationship building' and partnership working between YJB and YOT staff, leading to practice developments, rather than being led by a policy focus and partnership working 
emerging from formal structures and mechanisms such as the YJB EMG and the WYJAP. Processes of critical engagement are gaining a foothold and becoming accepted, embedded and valued across YOTs in Wales. Early engagement and supportive partnership has enabled the development of a flexible working relationship between YJB Cymru and YOTs, leading to an open, accessible and collaborative climate where, rather than viewing the YJB with 'suspicion and hostility', YOTs grant access to staff time, internal meetings and organisational commitment to projects, 'often at very short notice’. It would seem that increasing numbers of YOT staff in Wales are moving beyond an antiquated 'them and us' view of the YJB as a conspiratorial and punitive monitor and manager (at least where YJB Cymru are concerned) and are beginning to recognise the centralised governmental pressures placed on YJB Cymru, their role in seeking to mediate policy and practice in the Welsh context and their overarching desire to support and guide YOTs in Wales through reflective partnership working. Staff reflected on the nature of this relationship as enabling YOTs to be 'brought along with policy and practice initiatives, not done to’.

The development of relationships of reciprocal trust, respect and openness has created a working climate where YJB Cymru has been able to explain their objectives and the policy and practice development challenges they face (e.g. wider government policy) to YOTs, paving the way for YJB Cymru to be critical of YOT practice and to have this critique listened to and acted upon. For example, YJB Cymru staff have highlighted gaps in the data provided by YOTs and worked with them (often at the YOT's request) to offer support and guidance in developing more reliable data collection and reporting mechanisms. Reciprocally, YJB Cymru utilises centrally 
prescribed data monitoring processes to seed, embed and catalyse improvements to youth justice services and their consequent outcomes for young people. For example, The YJB gathers standardised performance statistics on a quarterly and annual basis relating to six Key Performance Indicators ${ }^{11}$ (KPIs), called 'National Indicators' in England and 'Youth Justice Indicators' (YJIs) in Wales. Interviewees from YJB Cymru and YOTs reflected the shared objective to employ data management to encourage and facilitate YOTs 'to establish the correct building blocks and foundations for their practices'.

YJB Cymru appears committed to encouraging Welsh YOTs to establish appropriate foundations, customs and practices (ways of working) before they generate evidence and pursue creative and innovative practice. To this end, the Effective Practice and Innovation Branch provides workforce support, guidance, toolkits and programme quality assurance and small pots of funding for projects that meet YJB criteria for practices and programmes leading to evidence that can be considered to be ‘emerging', 'promising' or 'research-proven' - as a catalyst for innovation and

\footnotetext{
${ }^{11}$ YJI 1: First time entrants: Rates of juveniles receiving their first reprimand, warning or conviction per 100,000 of the 10-17 year old population by Local Authority of residence.

YJI 2: Re-offending: The cohort consists of all young people who received a pre-court or court disposal or were released from custody over a 1 year period. Both the binary and frequency rates are available.

YJI 3: Use of custody: The indicator uses case level data and is the number of custodial sentences given in court to young people aged 17 years or younger presented as a rate per 1,000 young people in the 10 to 17 local general populations.

YJI 4: Engagement in education, training and employment for young people in the youth justice system: The percentage change in the average number of hours of suitable education, training or employment received while within the youth justice system by young people of statutory school age, and those above statutory school age.

YJI 5: Access to suitable accommodation for young people in the youth justice system: The percentage change in the proportion of young people with suitable accommodation at the end of their court order compared with before the start of their court order, and upon their release from custody compared with before the start of their custodial sentence.

Wales YJI 6: Access to substance misuse services for young people in the youth justice system: The percentage of young people identified as requiring a substance misuse assessment that commence the assessment within five working days of referral, and those identified as needing treatment or other intervention, who receive this within ten working days of assessment.
} 
practice evolution. The Effective Practice and Innovation Branch supports YOTs by identifying and promoting effective practice and areas for improvement (which are tailored to the Welsh social policy and youth justice contexts) through a 'Practice Development Panel $^{12}$, and regular detailed analysis of YOT plans. Consequently, all support and funding is underpinned by YJB Cymru requirements for YOTs to:

'get their practice foundations right before they produce evidence. Basic customs and practices have to be in place before reflection and then innovation’

The SIP findings regarding the YJB Cymru-Welsh YOTs relationship mirror those of Souhami (2011), namely that faced with incremental waves of new policies and procedures, YOTs increasingly turn to the YJB as its sole source of expert support increasing the 'flows of people, data and ideas between practice and central government' (Souhami 2011: 12). YJB Cymru uses data monitoring and evidence generation processes to provide guidance and support and to engineer privileged access to YOTs, beyond its original remit of being 'hands off' with local services (reflecting Souhami’s 2011 findings regarding the YJB of England and Wales). This practice is not viewed by key stakeholders (notably YOTs) as legitimising increased surveillance, control and intervention under the guise of a supportive relationship (unlike Souhami 2011), largely due to the nature of the critical engagement that underpins the YJB Cymru-YOT relationship. YOT staff generally viewed their relationship with YJB Cymru as beneficial, improving the quality of their data

\footnotetext{
${ }^{12}$ A multi-disciplinary panel containing representatives from YJB Cymru, YOT Managers Cymru, the secure estate, YOTs, the Welsh Government and Welsh universities. The panel meets quarterly to develop practice around set thematic foci such as health, compliance, prevention, education, engagement and dissemination.
} 
collection and analysis practice, enhancing their self-confidence and status/profile within local partnerships as a result of this improved (more robust) practice (c.f. HMI Probation 2011; Morgan 2009) and, most importantly, improving outcomes for their local children and young people.

Critical engagement with YOTs is an ongoing process of critical reflection and improvement. It will never be the finished article, nor will it be a seamless and unencumbered process devoid of obstacles. Engagement processes have not been, as yet, rolled out, embedded or engaged with across all YOTs. Inevitably, there are differing degrees of engagement with YJB Cymru, which vary across organisations, managers and individual staff, not to mention between individual areas of work within YOTs. This is the natural terrain in which YJB Cymru and YOTs have to work. Evidence from the SIP demonstrates a nascent culture shift in Wales away from (historical) small pockets of more limited engagement and towards more widespread and embedded reflective, critical engagement and open, reciprocal communication between YJB Cymru and YOTs. The SIP project identified evidence of a slow but committed process of critical engagement between YJB Cymru and YOTs in Wales, working together in more empathetic and accessible ways and viewing one another as providing expertise to enable Welsh-centric youth justice practice.

\section{YJB Cymru: Exercising strategic influence through critical engagement}

It is instructive to consider the role and processes of YJB Cymru in relation to the conclusions from Souhami's (2011) ethnographic study of the YJB for England and Wales parent organisation. Both configurations of the YJB (YJB England and Wales, YJB Cymru) retain a relative independence and distance from government that 
facilitates a critical friend role (which YJB Cymru has evolved into critical engagement), yet operate with an ambiguous, vacillating and slippery 'arms lengthhands on' identity in the eyes of both government (evidenced by recent legislative debate over abolition-maintenance-restriction) and YOTs (see Souhami 2013, 2011). YJB Cymru utilises its position in Wales to pursue a role of dual influence, offering 'independent' policy critique and guidance to government whilst drawing on this independence and distance to gain credibility with practitioners when providing advice and support. It is clear from the SIP data that YJB Cymru also utilises this role ambiguity to 'slip between positions' and to exert 'influence with different audiences both within and outside the youth justice system' (cf. Souhami's 2011 description of the role of the YJB for England and Wales) through critical engagement processes, only in their case with an even broader range of key stakeholders/partners. It would appear that YJB Cymru has developed a 'square of influence', broader than the dual influence of its English parent body and focused appropriately on critical engagement with four youth justice partners: UK Government, YJB for England and Wales, Welsh Government and ‘youth justice services’ (Welsh YOTs and the Secure Estate). YJB Cymru appears to face less risk of being 'cut adrift' from a policy influencing role and thus forfeiting its legitimacy in the eyes of practitioners if it is overly-critical of, or distanced from, government (an insecurity faced by the YJB in England and Wales Souhami 2011) due to its unique position within a partially devolved political context. Rather than dealing directly with UK Government, key to the role of YJB Cymru is to 'influence the influencer' and to 'critique the critic', working within the parent YJB structures (rather than with full independence or autonomy) to mediate and manage the delivery of youth justice in Wales. 
The SIP identified a YJB Cymru team that is appreciated by and appreciative of Welsh youth justice services committed to mediating the demands placed on YOTs in the dynamic and multi-faceted context of youth justice, particularly in Wales. The strategic influence, roles, relationships and identity/identities of YJB Cymru are evolving and dynamic processes. Crucially, they are processes that cannot achieve their potential without the support, commitment and guidance of the key stakeholders with whom YJB Cymru engages. SIP feedback (including reflection by YJB Cymru a key objective of the SIP) suggested that the expertise of YOT practitioners has yet to be fully realised by YJB Cymru. Similarly, there is a need to draw upon external expertise from key stakeholders new to the context of policy and practice development, such as academics and Secure Estate managers, although these relationships are beginning to evolve, for example, through the WYJAP, the Effective Practice Identification Panel and links with the Welsh Centre for Crime and Social Justice. However, the SIP findings make very clear that there is a growing trust, respect and empathy between YJB Cymru and key stakeholder groups (YOTs, Welsh Government, YOT Managers Cymru) and the shared desire to engage with one another in critical, reflective and practical ways benefit the delivery of youth justice nationally in Wales.

\section{Conclusion}

The central objectives of this paper were to explore the role of YJB Cymru in youth justice policy and practice development structures, processes and relationships, whilst providing the organization with the opportunity for self-reflection on their role and working practices. Analysis of the SIP identified that YJB Cymru has an increasingly important role in policy and practice development structures and processes in England 
and Wales more broadly (e.g. within the YJB for England and Wales) and in the Welsh national context specifically. YJB Cymru fulfills a role of dual influence working both with government (UK and Welsh) and youth justice practitioners (mainly YOT managers and staff) to mediate and manage youth justice tensions in the partially-devolved Welsh policy context through relationships of reflective and critical engagement. These relationships are not without their political and practical issues, an inevitability in such a complex and dynamic environment. However, the SIP data provides an overriding picture of YJB Cymru as an increasingly relevant, accessible and supportive organisation with the capacity to exert a growing strategic influence upon youth justice in Wales through critical engagement with and within key structures and processes of policy and practice development. 


\section{Bibliography}

Audit Commission (1996) Misspent Youth. London: Audit Commission.

Case, S.P. and Haines, K.R. (2012) Criminal Justice Matters, 88(1): 38-40.

Drakeford, M (2010) Devolution and Youth Justice in Wales. Criminology and Criminal Justice, Vol 10, (2), 137-154.

Haines, K.R. (2009) The Dragonisation of Youth Justice. In: W. Taylor, R. Hester and R. Earle (eds) Youth Justice Handbook. Cullompton: Willan.

Haines, K.R. and Case, S.P. (2011) Risks, rights or both? Evaluating the common aetiology of negative and positive outcomes for young people to inform youth justice practice. Social Work Review, 2: 109-122.

Haines, K.R., Case, S.P., Charles, A.D. and Davies, K. (2013) The Swansea Bureau: A Model of Diversion from the Youth Justice System. International Journal of Law, Crime and Justice. Vol. 41, Issue 2: 167-187.

HMI Probation (2011) Core case inspections of youth offending work. London: HMI Probation.

Ministry of Justice (2012) Youth Justice Board for England and Wales (Triennial Review). London: MOJ. 
Ministry of Justice (2010) Breaking the cycle: Effective punishment, rehabilitation and sentencing of offenders. London: MOJ.

Morgan, R. (2009) Report to the Welsh Assembly Government on the question of Devolution of Youth Justice Responsibilities. Cardiff: Welsh Assembly Government.

National Assembly Policy Unit (2002) Extending Entitlement: Support for 11 to 25 year olds in Wales. Direction and Guidance. Cardiff: National Assembly for Wales.

Pitts, J. (2001) Korrectional Karaoke: New Labour and the Zombification of Youth Justice, Youth Justice, 1(2): 3-16.

Souhami, A. (2011) Inside the Youth Justice Board: ambiguity and influence in New Labour’s youth justice. Critical Social Policy, 10(3): 7-16.

Strategic Insight Programme (2013) www.siprogramme.org.uk/en/ (Accessed December 2013).

UK Government (2011) Public Bodies Act. London: UK Government.

Welsh Assembly Government and Youth Justice Board (2004) All Wales Youth Offending Strategy. Cardiff: Welsh Assembly Government.

Welsh Government (2012) Green Paper: Proposals to improve services in Wales to 
better meet the needs of children and young people who are at risk of entering, or are already in, the Youth Justice System. Cardiff: Welsh Government.

Welsh Government (2011) Devolution of youth justice: Cabinet briefing. Cardiff: Welsh Government.

Welsh Government (2004) Rights to Action. Cardiff: Welsh Government.

YOT Managers Cymru (2013) www.yotmanagerscymru.org.uk (Accessed November 2013).

Youth Justice Board (2013) Youth Out-of-Court Disposals. Guide for Police and Youth Offending Services. London: YJB.

Youth Justice Board (2012a) YJB Corporate Plan 2012-15 and Business Plan 2012/13. London: YJB.

Youth Justice Board (2012b) A blueprint for promoting effective practice and improving youth justice performance in Wales. London: YJB.

Youth Justice Board (2012c) Youth Justice Board: Effective Practice Identification and Dissemination. London: YJB.

Youth Justice Board (2012d) Improving outcomes in community youth justice services. YJB Community Division Blueprint 2012. London: YJB. 
Youth Justice Board (2008) Key Elements of Effective Practice: Assessment, Planning Interventions and Supervision. London: YJB.

Youth Justice Board and Welsh Government (2014) Terms of Reference for the Wales Youth Justice Advisory Panel. London: YJB. 


\section{Biographical note}

Dr Stephen Case is an Associate Professor in the Centre for Criminal Justice and Criminology at Swansea University. His research interests include pursuing 'children first' alternatives to youth justice, social inclusion and developing reflective youth justice practice. 